Japanese Journal of Physiology, 29, 789-803, 1979

\title{
Factors Affecting Frequency Dependence of Resistance Observed in Healthy Lungs
}

\author{
Yoshimi Miyamoto, Kazuyoshi Saito, and Tomohisa Mikami \\ Division of Biomedical Control, Research Institute of Applied Electricity, \\ Hokkaido University, Sapporo, 060 Japan
}

\begin{abstract}
The frequency dependence of effective resistance of the respiratory system was studied in seated and supine healthy subjects by use of a forced oscillation technique for the purpose of estimating the distribution of regional ventilation. Effective resistance determined at respective FRC levels of both these body postures fell with an increase in the breathing frequency, although the frequency dependence of resistance $\Delta R / \Delta f$ was more dominant in the supine posture than when seated. The $\Delta R / \Delta f$ increased to an appreciable extent by reducing the lung volume in the seated posture, while in the supine position the value was relatively insensitive to the volume change. The chest wall vibration measured during the forced oscillation was found to be larger in amplitude in the basilar than in the apical regions, and the regional difference became less dominant by postural change from seated to supine. Transthoracic electrical impedance change measured during voluntary ventilations with different frequencies gave a slight frequency dependence when measured in the basilar region either in the seated or supine posture. The above results lead to the conclusion that an inhomogeneous distribution of time constants independent of gravity appears between the apex and the base, and the gravity-independent distribution of time constants, either interlobular or intralobular, would be a prime determinant of the frequency-dependent resistance.
\end{abstract}

The uneven ventilation appearing in healthy lungs may be classified into two types: the one arising in the anatomical units such as lobes, segments and subsegments, and the other observed between the lung regions in which mechanical properties are either dependent on or independent of gravity. ENGEL et al. (1974) suggested through compartment analyses of expired gases collected from peripheral airways after a breath of oxygen that the major factors causing uneven ventilation is inhomogeneity of mechanical time constants within the anatomical units.

On the other hand, SASAKI et al. (1977) found that the frequency dependence of compliance studied in healthy subjects was less dominant in an erect position

Received for publication March 22, 1979

宮本嘉巳, 斎藤和義, 三上智久 
than when supine. Since the dependence also increased in the seated posture by reducing the lung volume voluntarily, these authors postulated the cause of the phenomenon to be the volume difference of functional residual capacities between both these body postures. When the lung volume is reduced, both resistance and compliance increase. Thus, inhomogeneous distribution of time constants, the product of resistance and compliance, would be anticipated to arise in the lungs if the gas volumes contained in lung regions are different. The distribution of inspired gas to lung regions is believed to be determined primarily by the vertical gradient of pleural pressure and the nonlinear nature of the static pressure-volume relationship of the lungs (Milic-Emili et al., 1966). Hence, dispersion of time constants is anticipated to appear between the apical and basilar regions of upright lungs, and between the abdominal (anterior) and dorsal (posterior) sides of horizontal ones. Several workers, however, have suggested that there might be a regional difference in lung elasticity independent of gravity between the apical and basilar lobes (FARIDY et al., 1967; BAKE et al., 1967). Indeed, the preceding works reporting insensibility of closing volumes and capacities to posutral changes (LeBlanc et al., 1970; CRAIG et al., 1971; CORTESE et al., 1976) cannot be explained by gravitational effect alone, since the pleural pressure gradient per lung height is known to be constant regardless of body posture (MILIC-EMILI et al., 1966; KANEKO et al., 1966), while the lung height varies from posture to posture.

The present study was intended to estimate characteristics of inhomogeneous distribution of time constants appearing in healthy lungs and to analyze the influence of factors affecting the inhomogeneity, such as gravity or lung volume change. The time constant theory of OTIS et al. (1956) suggests that the effective resistance also falls with an increase in the breathing frequency when inhomogeneity of time constants appears, and several workers demonstrated experimentally such a dependence of airway resistance on patients with obstructive lung disease (Grimby et al., 1968; Cutillo et al., 1973; MiYамото et al., 1975). We measured the resistance of the total respiratory system using a forced oscillation technique at different frequencies and lung volumes in seated and supine subjects. Likewise, as in the case of dynamic compliance, the frequency dependent resistance tells nothing as to the locus where the inhomogeneity arises. In the present study, the distribution of regional ventilations to the lungs was estimated from circumference changes in the chest wall induced by forced oscillation and transthoracic electric impedance changes during voluntary ventilations with different frequencies.

\section{METHODS}

The subdivision of lung volumes and postural changes thereof were determined by spirometry. First, the functional residual capacity (FRC) was determined in a seated posture by use of the standard technique of body plethysmography (DUBoIs et al., 1956a). Next, the subject in the seated posture was connected to a 
13.5-liter spirometer of Benedict-Roth type; the $\mathrm{CO}_{2}$ absorption chamber was previously removed. Starting from the FRC, the subject inspired up to total lung capacity (TLC), then expired until residual volume (RV), then he occluded the airway. During the breath-holding period he converted his body posture from seated to supine, then repeated the vital capacity maneuver once more, and finally returned to the FRC. The lung volumes at both body postures could thus be determined by combining the FRC value obtained plethysmographically with the spirometer tracing. In order to avoid lung volume change caused by the respiratory quotient during the breath-holding period and $\mathrm{CO}_{2}$ accumulation in the spirometer, the measurement should be finished within an short a period as possible.

The acoustic impedance and resistance of the respiratory system in response to a sinusoidal transthoracic pressure change were determined using the apparatus shown schematically in Fig. 1. The subject breathed room air via a bypath consisting of a solenoid valve and short tubing with a large bore. Inspired and expired gas volumes were continuously monitored by integrating the output signals of a pneumotachograph which was inserted between the mouth and the valve. At the instant when the lung volume reached the level desired for measuring the impedance or resistance, the valve was closed and the airway was now connected to a piston pump designed to give a sinusoidal volume change. The pump began to displace to-and-fro with a stroke volume fixed at $50 \mathrm{ml}$ and a frequency previously set between a range from 0.9 to $7.2 \mathrm{~Hz}$. The pump was driven for 5 to $10 \mathrm{sec}$, and during the period the oscillatory pressure arising in the closed circuit was measured at the mouth together with the oscillatory flow through the pneumotachograph by respective manometers. Since the oscillation extended to a rather high range in the present study, inertance of the measuring system should be kept at as small a level as possible in order to avoid artifacts. For this purpose, the resistant element of the pneumotachograph of conventional Fleisch type was replaced by a

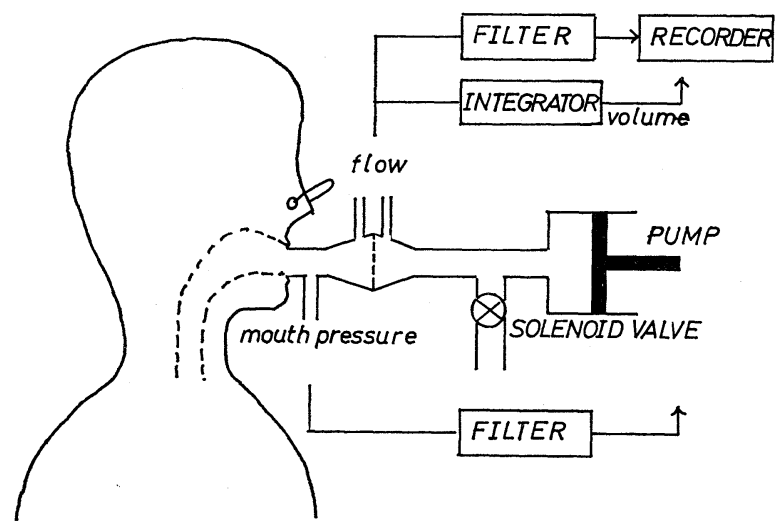

Fig. 1. Schematic representation of measuring apparatus. 
stainless steel mesh of 200 per inch and the connecting tubing between the pneumotachograph, pump, and valve was shortened as much as possible.

The oscillatory flow and pressure signals were displayed simultaneously on a recorder via appropriate band-pass filters to cancel undesired noises. Acoustic impedance was calculated by dividing the peak-to-peak amplitude of the pressure by that of the flow. Effective resistance was determined by taking the pressure swing corresponding to the inspiratory and expiratory peak points of the flow oscillation and dividing it by the peak-to-peak amplitude of the flow. The theoretical basis of this treatment has already been given by Goldman et al. (1970).

The thoracic circumference change in response to forced oscillation was measured by use of a saline-filled rubber tubing, $5 \mathrm{~mm}$ in diameter, $1 \mathrm{~mm}$ in thickness and $50 \mathrm{~cm}$ in length, wrapped around the thorax horizontally at the desired height level. The tubing was connected to one arm of a bridge circuit and its electric resistance change to stretch was detected. The output signals of the instrument were found to be linear up to an elongation of about $10 \mathrm{~cm}$, which was long enough to cover circumference change ranging over the full vital capacity. The chest wall oscillation was measured at two different height levels of the thorax, i.e., the upper level was at the horizontal line connecting both the armpits and the lower lay on the horizontal plane containing the xiphoid.

The electric impedance plethysmography adopted in the present study for the purpose of estimating the regional distribution of the ventilation was a tetrapolar electrodes system, one pair of which supplied a constant AC current of $350 \mu \mathrm{A}$ and $50 \mathrm{kHz}$, and the other detected potential drops induced by the current (Nihon-kohden, RGA-5). The current electrodes were placed along both the midaxillary lines, and the potential electrodes were located at anterior regions $3 \mathrm{~cm}$ distant from the current electrodes. These were fixed on the chest wall by a rubber band surrounding the thorax, of which the tension was adjusted so that it posed no serious restriction to respiratory movements. Measurements were usually made at the same height levels of the thorax at which chest wall vibrations were studied. Detailed explanations of impedance plethysmography and criticism of the reliability of this technique have been given in the succeeding paper (Miyamoto and Mikami). The subject was requested to make a series of tidal ventilations with different frequencies ranging between 0.2 and $1.2 \mathrm{~Hz}$. Tidal volumes during the measurement were adjusted voluntarily not to exceed a range between 300 and $700 \mathrm{ml}$.

The subjects consisted of healthy male laboratory staff and students, ranging in age from 23 to 50 years. Since the number of subjects studied varied from experiment to experiment, this will be given in the respective paragraphs concerning the results. All measurements were made in seated and supine postures successively with attention paid to minimizing alteration of the experimental conditions. 


\section{RESULTS}

\section{Effect of changes in body posture on lung volume}

Subdivisions of lung volume studied in seven subjects in seated and supine postures are given in Table 1. When the body posture was changed from upright to horizontal, the TLC, VC and FRC were reduced by $3.4 \%, 5.0 \%$ and $25.0 \%$, respectively while the $\mathrm{RV}$ remained unchanged.

Table 1. Subdivision of lung volumes determined in seated and supine postures.

\begin{tabular}{|c|c|c|c|c|c|}
\hline Subjects & Posture & TLC & RV & VC & FRC \\
\hline & & \multicolumn{4}{|c|}{ liters } \\
\hline \multirow[t]{2}{*}{1} & Seated & 6.24 & 1.63 & 4.60 & 3.20 \\
\hline & Supine & 6.03 & 1.65 & 4.37 & 1.97 \\
\hline \multirow[t]{2}{*}{2} & Seated & 6.38 & 1.01 & 5.36 & 3.00 \\
\hline & Supine & 6.08 & 0.88 & 5.20 & 2.42 \\
\hline \multirow[t]{2}{*}{3} & Seated & 6.17 & 2.30 & 3.87 & 3.00 \\
\hline & Supine & 6.13 & 2.33 & 3.80 & 1.80 \\
\hline \multirow[t]{2}{*}{4} & Seated & 6.36 & 1.29 & 5.06 & 3.60 \\
\hline & Supine & 6.27 & 1.24 & 5.02 & 2.72 \\
\hline \multirow[t]{2}{*}{5} & Seated & 6.52 & 1.18 & 5.34 & 3.60 \\
\hline & Supine & 6.34 & 1.18 & 5.16 & 2.88 \\
\hline \multirow[t]{2}{*}{6} & Seated & 5.43 & 1.54 & 3.89 & 2.60 \\
\hline & Supine & 5.25 & 1.63 & 3.61 & 2.30 \\
\hline \multirow[t]{2}{*}{7} & Seated & 4.42 & 0.89 & 3.52 & 2.30 \\
\hline & Supine & 4.07 & 1.14 & 2.92 & 1.90 \\
\hline Mean & Seated & 5.93 & 1.40 & 4.52 & 3.04 \\
\hline $\mathrm{SD}$ & & 0.69 & 0.43 & 0.70 & 0.44 \\
\hline Mean & Supine & 5.73 & 1.43 & 4.29 & 2.28 \\
\hline $\mathrm{SD}$ & & 0.75 & 0.44 & 0.81 & 0.38 \\
\hline
\end{tabular}

Frequency characteristics of the respiratory system

Acoustic impedance of the respiratory system in response to forced oscillation and the phase angle between oscillatory flow and pressure were determined in four subjects at respective FRC levels of seated and supine postures. The results are summarized in Figs. 2 and 3. Open circles and solid lines represent averaged values for the seated posture, while closed circles and dots indicate those for supine posture. These symbols will commonly be used in the following drawings when it becomes necessary to compare the results obtained from both body postures on the same scale. Bars along each point represent the range of standard deviation. The resonant frequency estimated from zero-crossing points of the frequencyphase angle relationships was $4.7 \mathrm{~Hz}$ for seated subjects and $4.1 \mathrm{~Hz}$ for supine, and the impedance determined at resonance were 3.9 and $6.5 \mathrm{cmH}_{2} \mathrm{O} /$ liter/sec for both postures, respectively. Although the postural difference between the impedance values was observed throughout the frequency range studied, it became somewhat insignificant at both the extremes. Specific conductance was also cal- 


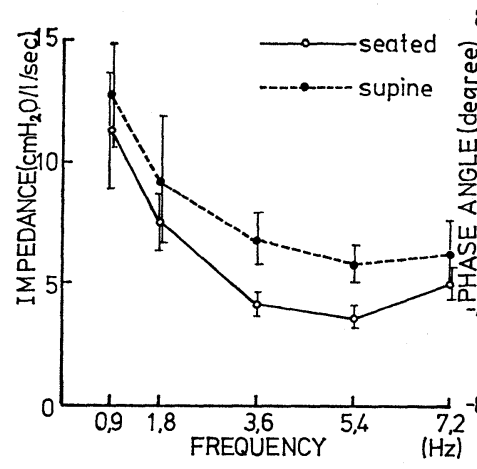

Fig. 2.

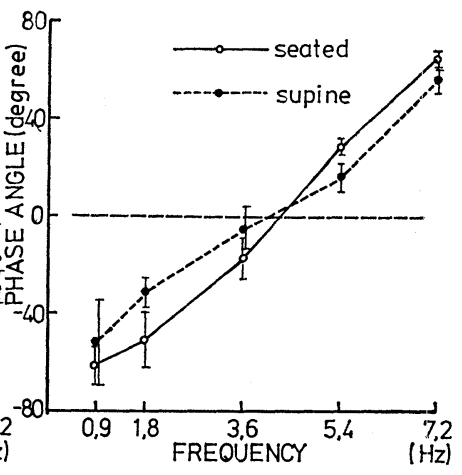

Fig. 3.

Fig. 2. Frequency responses of respiratory impedance determined at FRC.

Fig. 3. Phase angles between oscillatory pressure and flow determined in FRC.

culated by dividing the impedance value at resonance by the FRCs, these being 0.086 and $0.066 \mathrm{sec}^{-1} \mathrm{cmH}_{2} \mathrm{O}^{-1}$ for seated and supine postures, respectively.

The effect of changes in lung volume on the acoustic impedance in response to a fixed frequency of $5.4 \mathrm{~Hz}$ was further studied in four subjects. Since the frequency did not differ greatly from that of resonance, the impedance derived here would be assumed to be close to the effective resistance of the system. As was shown in Fig. 4, the impedance curves for both body postures decreased almost inversely in parallel with an increase in lung volume.

Frequency dependence of effective resistance of the respiratory system

The effective resistance of the respiratory system in response to forced oscillation ranging from 0.9 to $7.2 \mathrm{~Hz}$ was determined in four subjects at respective FRC levels of seated and supine postures. The results are summarized in Fig. 5. It appeared that the resistance decreased with an increase in the frequency in either body posture. The falling rate of the resistance per frequency $\Delta R / \Delta f$ seemed, however, somewhat superior in the supine posture than seated.

The frequency dependence of the resistance was further studied in two subjects with lung volume range extended to both extremes. As is shown in Fig. 6, $\Delta R / \Delta f$ seemed almost constant regardless of lung volume change when measured in the supine posture, while it increased in the seated position with a reduction in lung volume.

\section{Chest wall circumference change in response to oscillation}

Circumference change in the chest wall caused by forced oscillation of $5.4 \mathrm{~Hz}$ was studied in four subjects at different height levels of the thorax. In Fig. 7, relative changes of chest wall vibration $\Delta L / L_{0}$, where $\Delta L$ and $L_{0}$ represent the peakto-peak amplitude of the vibration and the circumference at full inspiration, respectively, are plotted against lung volume. The $\Delta L / L_{0}$ observed in the lower 


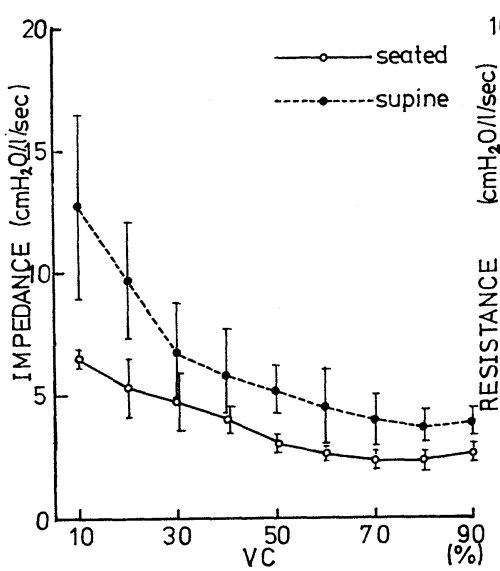

Fig. 4.

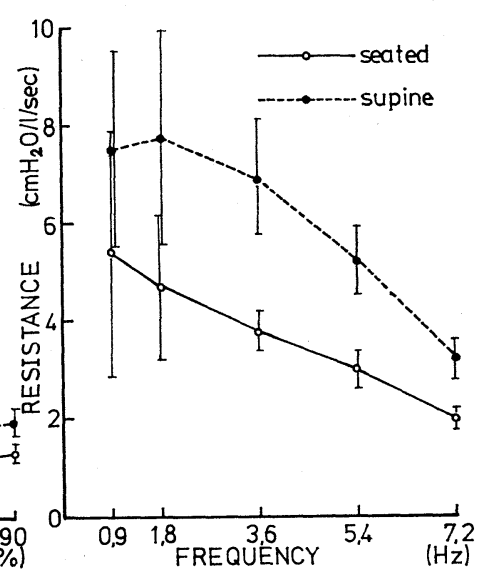

Fig. 5.

Fig. 4. Relationships between overall lung volume and acoustic impedance in response to oscillation of $5.4 \mathrm{~Hz}$.

Fig. 5. Frequency dependence of effective resistance determined in FRC.
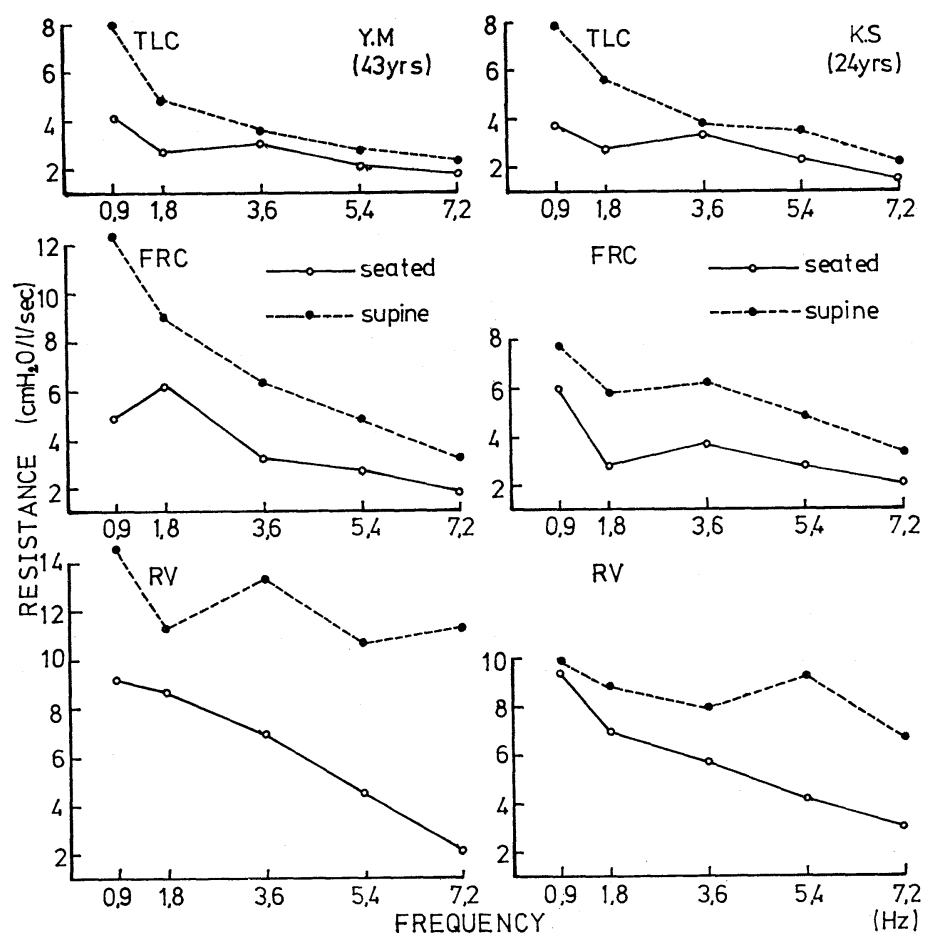

Fig. 6. Effect of changes in overall lung volume on frequency dependence of effective resistance studied in two subjects.

Vol. 29, No. 6, 1979 

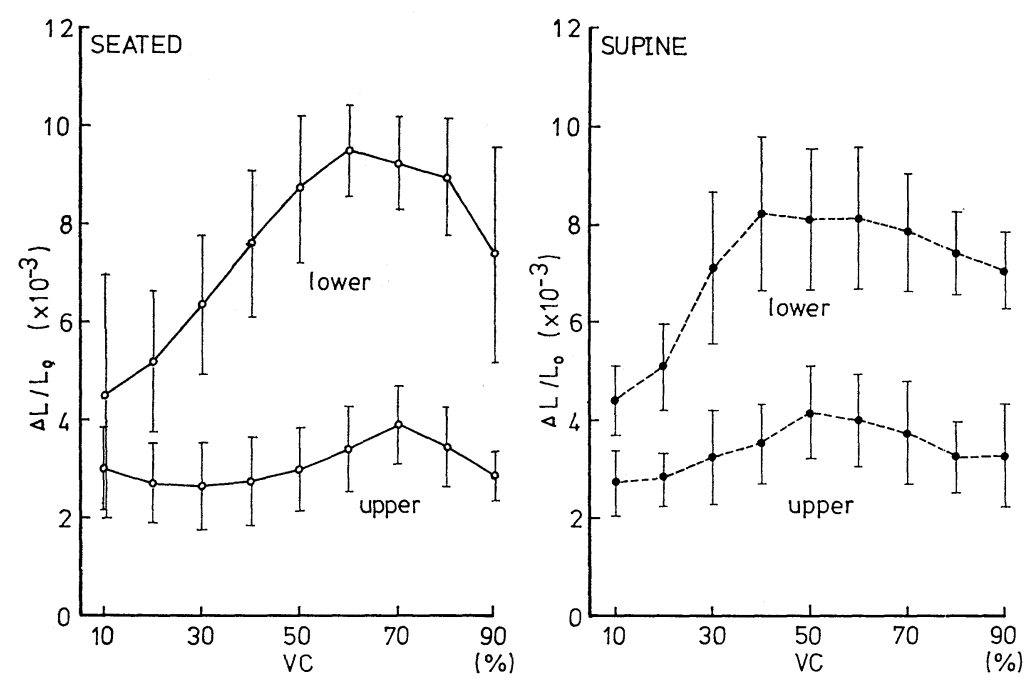

Fig. 7. Relationships between overall lung volume and circumference changes in chest wall in response to the oscillation of $5.4 \mathrm{~Hz}$ determined at upper (apical) and lower (basilar) regions.

(basilar) region was apparently greater than that for the upper (apical) region throughout the $\mathrm{VC}$ range measured in either both posture, although the regional difference seemed superior in the seated posture than in the supine. The $\Delta L / L_{0}$ for the lower region exhibited a tendency to decrease with lung volume when the lungs were deflated below a critical level; this corresponded to approximately $40 \%$ of the $\mathrm{VC}$ in supine posture and $60 \%$ in seated. Although a similar trend of the $\Delta L / L_{0}$ reduction was also observed in the curves for the upper region, this was far less dominant in comparison with the case of the lower region. The $\Delta L / L \Delta_{0}$ for both regions also became small when the lungs were inflated near the full vital capacity.

Regional ventilation estimated by impedance plethysmography

In Fig. 8 are given electric impedance changes of the thorax in response to ventilation with different frequencies studied in eight seated subjects. Although comparisons among absolute values of the impedance seem physiologically meaningless because of the individual and regional differences of impedance sensitivity, the frequency dependence of impedance for a given region may be assumed to reflect relative changes in regional ventilation. The right panels summarize results obtained from subjects with the cigarette-smoking habit, and the left panels those from non-smokers. Except for both the cases of a young smoker and a middleaged non-smoker, impedance measured in the lower (basilar) region commonly exhibited a slight tendency to decrease with increasing breathing frequency. The most obvious frequency dependence was observed in subject Y. K., a middle-aged 


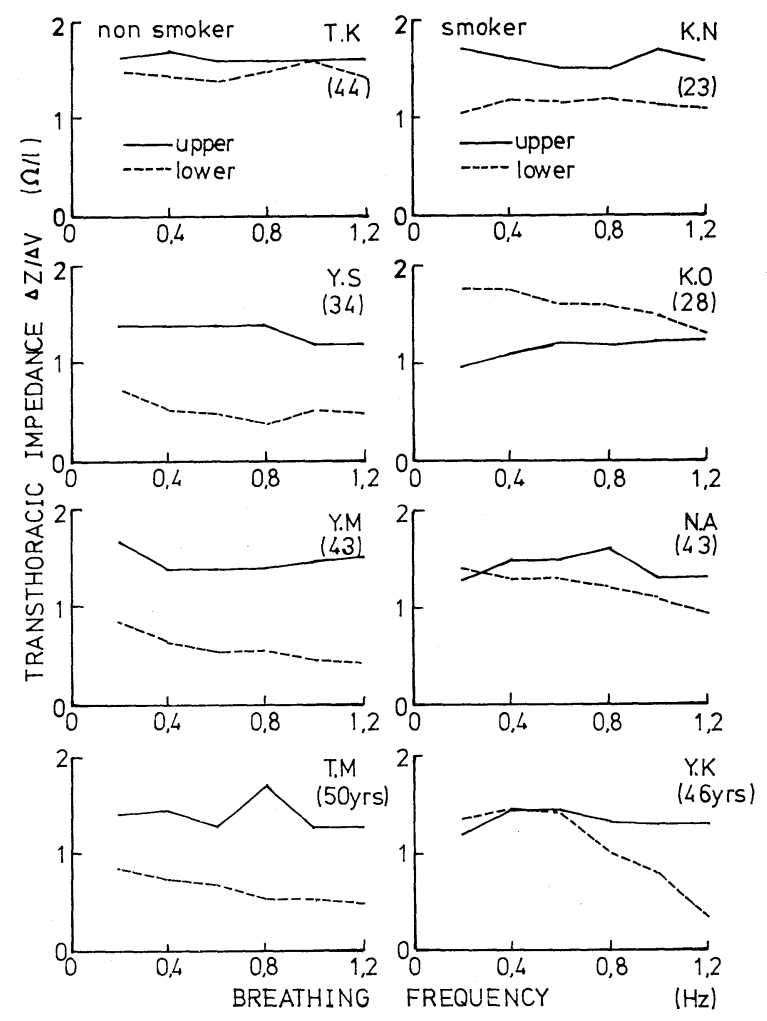

Fig. 8. Frequency dependence of transthoracic electric impedance changes measured at upper (apical) and lower (basilar) regions during voluntary ventilations. Smoking histories are: sub. K.N., 5 cigarettes per day for 5 years; K.O., 20/day, 10 years; N.A., 20/ day, 26 years; and Y.K., 20/day, 28 years.

smoker. On the other hand, there appeared no significant frequency dependence in the impedance change for the upper region. The frequency dependence of impedance was also studied in the supine posture, the results of which, however, were not significantly different from those of the seated posture.

\section{DISCUSSION}

Lung volumes were observed to decrease with the postural change from seated to supine, obviously in the FRC and slightly in both the TLC and RV. The results were in good accordance with the preceding work reviewed by BRISCOE (1965). There are three reasons why lung volume should change in the supine posture: 1) The diaphragm elevates up to its maximally cephalad position since the downward pull on the diaphragm by the weight of the abdominal contents is now removed; 2) the transverse and anteroposterior diameters of the chest increase; and 3 ) the systemic blood is poured out of the dependent veins when supine and is 
stored in the lungs. Most observers invoke the third mechanism to explain the reduced lung gas volume in the supine posture. The motility reflex of the chest to enlarge the thorax would not be strong enough to compensate for the volume reduction caused by pulmonary congestion.

The resonant frequency of the respiratory system was found to lie between 4 and $5 \mathrm{~Hz}$, common in both body postures. This was compatible with $4.5-7 \mathrm{~Hz}$ reported by PESLIN et al. (1975), $5.8 \mathrm{~Hz}$ by DuBors et al. (1956b), 5-8 Hz by FisHER et al. (1968) and 5-7 Hz by GRIMBY et al. (1968), but is slightly lower than $8 \mathrm{~Hz}$ observed by MiCHAELSON et al. (1975) and LÁNDSÉR et al. (1976). Resistance at the FRC determined from impedance at resonance was 3.9 and $6.5 \mathrm{cmH}_{2} \mathrm{O} /$ liter/sec in the seated and supine postures, respectively. The present resistance value for the seated posture was slightly higher than those appearing in the literature, many of which gave an order of 2 to $3 \mathrm{cmH}_{2} \mathrm{O} /$ liter/sec (FISHER et al., 1968; GRIMBY et al., 1968; Goldman et al., 1970; Michaelson et al., 1975; PeSlin et al., 1975; STǍNESCU et al., 1975; ARONSSON et al., 1977). On the other hand, published data for resistance studied in the supine posture are scarce. The present value was slightly higher than $4.6 \mathrm{cmH}_{2} \mathrm{O} /$ liter/sec reported by DuBoIs et al. (1956b) but much lower than $9 \mathrm{cmH}_{2} \mathrm{O} /$ liter/sec by BERGMAN and WALTEMATH (1974) who studied anesthetized, paralyzed and artificially ventilated subjects. Since the specific conductance was found to be still greater in the seated posture than in the supine by about $30 \%$, the postural difference of the resistance values cannot be solely explained by changes in the FRC appearing in the seated and supine postures. HogG et al. (1972) found in dogs that raising the left atrial pressure increased the resistance of peripheral airways at a given lung volume. These workers suggested that there could be competition for space between the vessel and airways in the broncovascular sheath of the lungs. When the vessels dilate in size by pulmonary vascular congestion, this may compress the airways and increases their resistance. The present results may support this suggestion since the pulmonary capillary blood volume is generally believed to increase in the supine posture. However, there remains the possibility that other factors, such as constriction of upper airways or an increase in the muscular tone of the thorax caused by the vagus reflex, may contribute to increase the resistance of conscious humans in the supine posture. A change is relative position among the lungs, diaphragm and abdominal contents should occur in the trunk when supine, and this may also be responsible for the phenomenon. Unfortunately, we have now no satisfactory data to quantitate the complicated correlationship among these factors.

The measurement of frequency dependence of dynamic compliance is believed to be one of the adequate techniques for the purpose of detecting the uneven distribution of time constants. However, as was partially reviewed by SASAKI et al. (1977), the question of whether esophageal pressure obtained with the balloon technique could be an accurate representation of pleural pressure in the supine posture was not fully resolved, since the mediastinal structure might compress 
the esophagus. Although the frequency-dependent resistance obtained by the present forced oscillation technique seems free from the point discussed above, it also involves several problems that can be criticized. First, the frequency dependence of the pulmonary resistance may be influenced by the tissue resistance of the thorax if it also varies with frequency since the oscillation technique measures total respiratory resistance. Albright and BondurAnt (1965) observed such a frequency dependence of the chest wall resistance in seated subjects who were artificially ventilated in a body respirator with a frequency up to $2 \mathrm{~Hz}$. On the other hand, GRIMBY et al. (1968) demonstrated on healthy and diseased upright subjects a flat response of the chest wall resistance in a range from 3 to $9 \mathrm{~Hz}$ using the forced oscillation technique. We suppose that the discrepancy may have been caused by the volume difference of the ventilation in the techniques adopted since the displacement of the chest wall in response to forced oscillation is usually far less than that appearing in the body respirator, although there remains a possibility that the chest wall resistance is actually frequency-dependent at a range less than $2 \mathrm{~Hz}$. Secondly, the reactance component involved in the acoustic networks of the respiratory system may influence the effective resistance. FInUCANE et al. (1975) observed that resistance of peripheral airways of healthy subjects consistently increased with frequency. These authors attributed the cause thereof to inhomogeneity of the lung mechanics chiefly due to distensible airway walls that have both capacitive and inertial reactance. This effect seems, however, not so serious in the measurement on the total respiratory system since MicHAELSON et al. (1975) did not observe such an increase in resistance on his healthy subjects up to $50 \mathrm{~Hz}$, and the same was true for LÁNDSÉR et al. (1976), at least up to $10 \mathrm{~Hz}$. Although inertance of the respiratory system, which is chiefly due to the mass of the thorax and that of oscillatory gases in the airways, is reported to influence the frequency dependence of dynamic compliance (BOBBAERS et al., 1975), the inertial effect on resistance is believed to be negligible (FInUCAN et al., 1975; Tsai et al., 1977).

Although frequency dependence of resistance is generally accepted to appear in patients with obstructive lung disease, the majority of previous works including our previously published reports failed to demonstrate such a dependence in healthy subjects (Grimby et al., 1968; Cutillo et al., 1973; МiYAMото et al., 1975; STǍNESCU et al., 1975). A few investigators, however, found a slight decrease in resistance with increasing frequency in healthy subjects, i.e., LÁNDSÉR et al. (1976) in upright subjects in a frequency range up to $8 \mathrm{~Hz}$ and TsAI et al. (1977) in supine dogs up to $16 \mathrm{~Hz}$. We suppose an inertial component involved in the measuring apparatus may be partially responsible for the discrepancy. We found in a preliminary experiment that the conventional Fleisch-type pneumotachograph was inadequate for the present purposes because the phase shift between the oscillatory pressure and flow considerably increased in a frequency range higher than $5.4 \mathrm{~Hz}$. Since the inhomogeneity of time constants that would appear 
in healthy lungs is considered to be far smaller in comparison with that appearing in diseased lungs, a slight change in resistance may be masked if the additional inertance of the apparatus is dominant.

As was shown in Fig. 6 , the falling rate of resistance per frequency $\Delta R / \Delta f$ seemed to increase with a reduction in the lung volume when observed in the upright posture, while the $\Delta R / \Delta f$ for the supine posture was found to be relatively insensitive to lung volume change. MichaElson et al. (1975) had already found a quite similar dependence of the $\Delta R / \Delta f$ on lung volume in his upright healthy subjects. The resistance measured here is considered to consist of frequencydependent and -independent components, each being connected in series. It seems likely that the contribution ratio of the frequency-independent component to the total resistance would be inversely proportional to lung volume in the supine posture, while the ratio remains almost unchanged within a small range in seated subjects. Although any conclusive suggestion should be avoided at the present time, we speculate that the vagus reflex to constrict the upper airway may play a role in increasing the frequency-independent resistance. The inhomogeneity of lung mechanics, which is believed to be responsible for the frequency-dependent component of resistance, may also be classified into two types, one being dependent on gravity and the other being independent of it. The gravity-dependent inhomogeneity appearing in the upright lungs between the apex and base should disappear when supine, and instead, another inhomogeneity should appear along the anteroposterior direction between the abdominal and dorsal sides of horizontal lungs. An increase in the $\Delta R / \Delta f$ observed in the low extreme volume range of upright lungs seems to reflect the closure of peripheral airways of dependent regions and the resultant increase in the time constant dispersion. The closing phenomenon of the airways should, however, exert little effect on the frequency-dependent behavior of resistance in horizontal lungs, because the $\Delta R / \Delta f$ observed in the supine posture was almost unaffected by lung volume change. In other words, the frequency-dependent resistance appearing in the supine posture and that observed in the higher volume range of upright lungs should chiefly be caused by gravityindependent inhomogeneity, most of which would probably arise in the anatomical units of the lungs. Findings derived from the compartment analysis of inert gas distribution to lung regions partially reviewed in the introduction support this suggestion. In addition to this, there could be the contribution of interlobular inhomogeneity that might also appear independent of gravity. FARIDY et al. (1967) found a slight difference between static pressure-volume curves obtained from apical and basilar lobes of excised dog lungs. BAKE et al. (1967) found in intact supine human subjects an uneven distribution of inspired radioactive xenon between apical and basilar lobes, and assigned its cause to the difference in the elastic properties of these regions. The present results suggest that gravity-independent inhomogeneity, either interlobular or intralobular, occupies a large fraction of the total inhomogeneity that would be responsible for the frequency- 
dependent resistance.

The relative circumference changes in the chest wall in response to forced oscillation $\Delta L / L_{0}$ were found to be greater at the basilar zone than at the apical in both body postures although the regional difference became somewhat less dominant in the supine posture. $\Delta L / L_{0}$ is considered to reflect predominantly the regional elastic property of the lungs, if it may be assumed that the variable is proportional to the regional gas volume change. The present result seems to suggest that a difference may exist independent of gravity between regional compliances of the apical and basilar lobes. We found further that $\Delta L / L_{0}$ for the basilar region decreased progressively when the lungs were deflated below a critical volume. This seems to suggest that the closure of peripheral airways takes place on a cue from lung volume since regional ventilation is also influenced by regional resistance as well as by compliance when the frequency is sufficiently high.

Strictly speaking, $\Delta L / L_{0}$ cannot be a measure of regional gas volume change, since the contribution of the diaphragm to ventilation is essentially not included in this term. The transthoracic electric impedance change is known to reflect both the volume changes of blood and gas in the chest. In the present study, the electrode system was so arranged that blood volume change originating in cardiac events should make only a minor contribution to the total impedance change of the lungs. However, it was still difficult for us to follow the impedance change during forced oscillation precisely because of the limitation of pump stroke volume. Hence, we measured the regional impedance change in response to a series of voluntary ventilations with different frequencies. The fractional distribution of ventilation to a region with higher time constant is anticipated to decrease with an increase in the breathing frequency and to the same extent as reduction the distribution of regions with lower time constants would increase. We found a slight frequency dependence in the impedance change for basilar regions. This seems to support the suggestion mentioned above that there could be a regional difference in time constants among the basilar and other regions of the lungs. Since we failed to demonstrate any postural change in the frequency-dependent impedance, the interlobular dispersion of time constants seems relatively insensitive to gravity. JONES et al. (1977) found through the study of the regional distribution of inhaled radioactive xenon on seated subjects that the ventilation appearing in lower regions became smaller at $60 \mathrm{breath} / \mathrm{min}$ than at $10 \mathrm{breath} / \mathrm{min}$ in patients with chronic obstructive lung disease, while the breathing frequency had no significant effect on the ventilation distribution in healthy subjects. This was in good accordance with our observation that the frequency dependence of the impedance appeared predominantly in the aged subjects with the smoking habit.

Conclusive suggestions drawn from the present study may be summarized as follows: 1) There appears an inhomogeneous distribution of time constants independent of gravity between the apical and basilar lobes of healthy lungs; 2) the gravity-independent interlobular inhomogeneity of time constants as well as the 
intralobular ones that would appear in the anatomical units are prime determinants for the frequency-dependent resistance of the lungs; and 3) gravity accelerates the interlobular inhomogeneity between the apex and base of vertical lungs to an appreciable extent in a reduced lung volume.

This work has been supported in part by Governmental grant No. 357278 (to Dr. Miyamoto) in aid for fundamental scientific research.

\section{REFERENCES}

Albright, C. D. and Bondurant, S. (1965) Some effects of respiratory frequency on pulmonary mechanics. J. Clin. Invest., 44: 1362-1370.

Aronsson, H., Solyman, L., Dempsey, J., Buure, J., Olsson, T., and Bake, B. (1977) A modified forced oscillation technique for measurements of respiratory resistance. J. Appl. Physiol., 42: $650-655$.

Bake, B., Buure, J., Grimby, G., Milic-Emili, J., and Nilsson, N. J. (1967) Regional distribution of inspired gas in supine man. Scand. J. Respir. Dis., 48: 189-196.

Bergman, N. A. and Waltemath, C. L. (1974) A comparison of some methods for measuring total respiratory resistance. J. Appl. Physiol., 36: 131-134.

Bobbaers, H., Clement, J., Pardaens, J., and van de Woestijne, K. P. (1975) Simulation of frequency dependence of compliance and resistance in healthy man. J. Appl. Physiol., 38: 427-435.

Briscoe, W. A. (1965) Lung volumes. In: Handbook of Physiology, Respiration, Vol. II, ed. by Fenn, W. O. and Rahn, H. Am. Physiol. Soc., Washington, D.C., pp. 1345-1379.

Cortese, D. A., Rodarte, J. R., Rehder, K., and Hyatt, E. R. (1976) Effect of posture on the single-breath oxygen test in normal subjects. J. Appl. Physiol., 41: 474-479.

Craig, D. B., Wahba, W. M., Don, H. F., Couture, J. G., and Becklake, M. R. (1971) 'CClosing volume" and its relationship to gas exchange in seated and supine positions. J. Appl. Physiol., 31: 717-721.

Cutillo, A., Omboni, E., Perondi, R., and Tana, F. (1973) Pulmonary resistance and respiratory frequency in chronic airways obstruction. J. Appl. Physiol., 35: 122-128.

DuBois, A. B., Botelho, S. Y., Bedell, G. N., Marshall, R., and Comroe, J. H., Jr. (1956a) A rapid plethysmographic method for measuring thoracic gas volume. J. Clin. Invest., 35 : 322-326.

DuBois, A. B., Brody, A. W., Lewis, D. H., and Burgess, B. F., Jr. (1956b) Oscillation mechanics of lungs and chest in man. J. Appl. Physiol., 8: 587-594.

Engel, L. A., Utz, G., Wood, L. D. H., and Macklem, P. T. (1974) Ventilation distribution in anatomical lung units. J. Appl. Physiol., 37: 194-200.

FARIDY, E. E., KIDD, R., and Milic-Emil, J. (1967) Topographical distribution of inspired gas in excised lobes of dogs. J. Appl. Physiol., 22: 760-766.

Finucane, K. E., Dawson, S. V., Phelan, P. D., and Mead, J. (1975) Resistance of intrathoracic airways of healthy subjects during periodic flow. J. Appl. Physiol., 38: 517-530.

Fisher, A. B., DuBois, A. B., and Hyde, R. W. (1968) Evaluation of the forced oscillation technique for the determination of resistance to breathing. J. Clin. Invest., 47: 2045-2057.

Goldman, M., Knudson, R. J., Mead, J., Peterson, N., Schwaber, J. R., and Wohl, M. E. (1970) A simplified measurement of respiratory resistance by forced oscillation. J. Appl. Physiol., 28: 113-116.

Grimby, G., Takishima, T., Graham, W., Macklem, P., and Mead, J. (1968) Frequency dependence of flow resistance in patients with obstructive lung disease. J. Clin. Invest., 47: 
1455-1465.

Hogg, J. C., Agarawal, J. B., Gardiner, A. J. S., Palmer, W. H., and Macklem, P. T. (1972) Distribution of airway resistance with developing pulmonary edema in dogs. J. Appl. Physiol., 32: 20-24.

Jones, R. L., Overton, T. R., and Sproule, B. J. (1977) Frequency dependence of ventilation distribution in normal and obstructive lungs. J. Appl. Physiol., 42: 548-553.

Kaneko, K., Milic-Emilt, J., Dolovich, M. B., Dawson, A., and Bates, D. V. (1966) Regional distribution of ventilation and perfusion as a function of body position. J. Appl. Physiol., 21: 767-777.

Lándsér, F. J., Nagels, J., Demedts, M., Billiet, L., and van de Woestijne, K. P. (1976) A new method to determine frequency characteristics of the respiratory system. J. Appl. Physiol., 41: 101-106.

Leblanc, P., Ruff, F., and Milic-Emili, J. (1970) Effects of age and body position on "airway closure" in man. J. Appl. Physiol., 28: 448-451.

Michaelson, E. D., Grassman, E. D., and Peters, W. R. (1975) Pulmonary mechanics by spectral analysis of forced random noise. J. Clin. Invest., 56: 1210-1230.

Milic-Emili, J., Henderson, J. A. M., Dolovich, M. B., Trop, D., and Kaneko, K. (1966) Regional distribution of inspired gas in the lung. J. Appl. Physiol., 21: 749-759.

Miyamoto, Y., Saizen, N., and Mikami, T. (1975) Dependency of pulmonary resistance and compliance on breathing frequency. Monogr. Ser. Res. Inst. Appl. Electr., Hokkaido Univ., 22: 29-39.

Otis, A. B., Mckerrow, C. B., Bartlett, R. A., Mead, J., McIlroy, M. B., Selverstone, N. J., and RADFORD, E. P., Jr. (1965) Mechanical factors in distribution of pulmonary ventilation. J. Appl. Physiol., 8: 427-443.

Peslin, R., Papon, J., Duvivier, C., and Richalet, J. (1975) Frequency response of the chest: Modeling and parameter estimation. J. Appl. Physiol., 39: 523-534.

SASAKI, H., HIDA, W., and TAKISHIMA, T. (1977) Influence of body position on dynamic compliance in young subjects. J. Appl. Physiol., 42: 706-710.

Stǎnescu, D. C., Fesler, R., Veriter, C., Frans, A., and Brasseur, L. (1975) A modified measurement of respiratory resistance by forced oscillation during normal breathing. $J$. Appl. Physiol., 39: 305-311.

Tsai, M. J., Pimmel, R. L., Stiff, E. J., Bromberg, P. A., and Hamlin, R. L. (1977) Respiratory parameter estimation using forced oscillatory impedance data. J. Appl. Physiol., 43: 322-330. 